\title{
OVER-EXPRESSION OF A GELATINASE A ACTIVITY IN KERATOCONUS
}

\author{
V. A. SMITH, H. B. HOH, M. LITTLETON and D. L. EASTY \\ Bristol
}

\begin{abstract}
SUMMARY
Keratoconus is an ocular disorder in which the central cornea becomes thin, conical and frequently scarred. We are exploring the possibility that this condition is induced and maintained by proteases that exist in the corneal matrix in an activated form. In this study, the activities of the proteases secreted in vitro and in vivo by keratocytes of normal, clear keratoconic, scarred keratoconic and traumatically scarred corneas have been compared and partially characterised. Data obtained by assaying acyl transferase activity showed that the matrix metalloproteinases account for a minimum of $95 \%$ of the total protease secreted by cultured keratocytes. Their summated specific activity was consistently and significantly higher in the culture medium of keratoconic keratocytes than in the medium of other keratocyte cultures. Analysis of the individual protease activities secreted by these corneal keratocytes in vitro and in vivo by SDS-gelatin polyacrylamide gel electrophoresis showed that a gelatinase of molecular weight 65000 is the major protease secreted by normal keratocytes. Whereas clear keratoconic and traumatically scarred corneal keratocytes secrete an additional activity of molecular weight $61 \mathrm{000}$, scarred keratoconic corneal keratocytes generally produced little or none of this gelatinase activity. Both activities may be ascribed to gelatinase $A$, and although the 61000 molecular weight form may be a significant feature of keratoconus, neither appears to be active as secreted.
\end{abstract}

Keratoconus is a non-inflammatory corneal disorder that particularly affects young adults at a frequency of 1 per 1000 individuals $^{1}$ and is characterised by progressive thinning and scarring of the central cornea. At the onset of keratoconus, the induced irregular astigmatism may be corrected with contact lenses. Ultimately, a large proportion of keratoconic patients require corneal grafts to restore vision and

Correspondence to: $\operatorname{Dr}$ V. A. Smith, Department of Ophthalmology, Bristol Eye Hospital, Lower Maudlin Street, Bristol BS1 2LX, UK. they represent a major group (approximately 20\%) of patients who receive donor corneas. ${ }^{2}$

Ultrastructural characteristics of keratoconic corneas include fragmentation of Bowman's layer, fragmentation of the epithelial cell basement membrane and fibrillation of the anterior stroma. ${ }^{3-5}$ The possibility that these pathological features are a result of enhanced matrix metalloproteinase (MMP) activity has been investigated previously, but the published results are conflicting. ${ }^{6-9}$ Furthermore, in the studies that have found MMP activity to be greater in keratoconic corneas than in normal corneas, the possibility that this increase relates to the wound-healing and repair mechanisms, rather than a direct effect of the primary disease, was not clarified.

The aim of the present investigation was, therefore, to partially characterise the complement of proteases secreted by corneal keratocytes in vitro and in vivo and to assess their status in normal, keratoconic and scarred corneas.

\section{METHODS}

\section{Experimental Material}

Specimen corneas were either donated by $\mathrm{Mr} \mathrm{A}$. Tullo, Manchester Eye Hospital, or obtained from Bristol Eye Hospital Theatre and Eye Bank. To distinguish between inductive and secondary biochemical processes that correlate with the pathology of keratoconus, specimen keratoconic corneal buttons were divided into two groups comprised of either non-scarred $(\mathrm{KCS})$ or scarred $\left[\mathrm{KCS}_{(\mathrm{scar})}\right]$ tissue. In addition, for comparative purposes, normal and traumatically scarred [Scar (trauma) corneal tissues were also utilised.

\section{Cell Culture}

Epithelial cell layers were stripped from their underlying corneal stroma prior to dicing these tissues in small quantities of Dulbecco's MEM growth medium supplemented with fetal calf serum 
(FCS, 10\%), glutamine, glucose (Gibco) and antibiotic, antimycotic mixture (Sigma). The explants were seeded into $25-\mathrm{ml}$ culture flasks and grown to confluence in the same medium $(3 \mathrm{ml})$. On achieving confluence, the FCS was omitted from the culture medium for intermittent periods of 4 days. These media samples were collected for further processing.

\section{Protease Preparations from Keratocyte Culture Media}

Proteins secreted during the 4-day incubation period in serum-free media were precipitated with ammonium sulphate, added as a saturated solution in $10 \mathrm{mM}$ potassium phosphate buffer, $\mathrm{pH} \mathrm{7.2,} \mathrm{to} \mathrm{a} \mathrm{final}$ concentration of $70 \%(\mathrm{w} / \mathrm{v})$. All solutions were left at $4{ }^{\circ} \mathrm{C}$ for a minimum period of 24 hours before centrifuging at $20000 \mathrm{~g}$ for 1 hour at $4{ }^{\circ} \mathrm{C}$. After decanting the supernatants, the pelleted proteins were redissolved in $0.01 \mathrm{M}$ potassium phosphate, $\mathrm{pH} 7.2$ containing $0.2 \mathrm{M} \mathrm{NaCl}$ and $10 \%(\mathrm{v} / \mathrm{v})$ glycerol, and stored at either $-20{ }^{\circ} \mathrm{C}$ (short term) or $-85{ }^{\circ} \mathrm{C}$ (long term).

\section{Protease Extraction from Corneal Stromal Tissue}

Prior to extraction, the specimen corneal tissues were stored in liquid nitrogen. They were then pulverised in liquid nitrogen using a small ceramic mortar and pestle, and homogenised in $0.01 \mathrm{M}$ potassium phosphate buffer, $\mathrm{pH} 7.4$, containing $0.2 \mathrm{M}$ sodium chloride. Homogenates were transferred to Eppendorf tubes and centrifuged for 10 minutes to pellet insoluble material. The supernatants were removed and, after the addition of glycerol $(10 \% \mathrm{v} / \mathrm{v}$, final concentration), were stored for assaying at $-20{ }^{\circ} \mathrm{C}$.

\section{Enzyme Assays}

Acyl transferase activity. All proteases possess acyl transferase activity and will catalyse the liberation of 4-nitrophenol from 4-nitrophenyl acetate. Substrate stocks $(0.5 \mathrm{mM})$ were prepared in dimethyl sulphoxide (DMSO). The enzyme preparations were assayed against this substrate $(0.025 \mathrm{mM})$ in $0.01 \mathrm{M}$ potassium phosphate buffer, $\mathrm{pH} 7.2$ containing $0.2 \mathrm{M}$ sodium chloride in a total volume of $1 \mathrm{ml}$. The kinetics of nitrophenol production (calculated $\mathrm{E}_{340}=$ 7620) was followed spectrophotometrically at $37^{\circ} \mathrm{C}$.

Substrate gel electrophoresis. The gelatinases secreted by the various keratocyte cultures were separated and visualised after electrophoresis on polyacrylamide gels $(8.5 \%)$ containing gelatin $(1 \mathrm{mg} /$ $\mathrm{ml}$ ), as described by Unemori and Werb. ${ }^{10}$ The sample solutions contained the ionic detergent SDS $(1 \% \mathrm{w} / \mathrm{v})$ and glycerol $(10 \% \mathrm{v} / \mathrm{v})$, and were applied to the gels without boiling or reduction. After electrophoresis, the gels were incubated in Triton $\mathrm{X}-100(2.5 \% \mathrm{v} / \mathrm{v})$ for 30 minutes at $37{ }^{\circ} \mathrm{C}$, rinsed in distilled water and then incubated for approximately 16 hours in $50 \mathrm{mM}$ Tris $\mathrm{HCl}, \mathrm{pH} \mathrm{7.4}$, containing
$5 \mathrm{mM}$ calcium chloride and $0.02 \%(\mathrm{w} / \mathrm{v})$ sodium azide. After rinsing with distilled water, they were then stained with Coomassie Blue $[2.5 \% \mathrm{w} / \mathrm{v}$ in an aqueous solution of methanol $(45 \%)$ and glacial acetic acid (10\%)], and destained with aqueous methanol/acetic acid $(5 \%$ and $7.5 \% \mathrm{v} / \mathrm{v}$, respectively).

\section{Protein Estimation}

Protein concentration was estimated spectrophotometrically from the relationship $\mathrm{OD}_{225} 9.18=1.0 \mathrm{mg} /$ $\mathrm{ml}^{11}$

\section{RESULTS}

For the purposes of this comparative investigation of the proteases that are secreted by cultured corneal keratocytes and are present in intact corneal tissue, keratocyte cultures were prepared from 8 normal (age range 17-84 years), 4 non-scarred keratoconic (28-34 years), 4 scarred keratoconic (22-48 years) and 4 traumatically scarred (27-66 years) corneal buttons. In addition, the tissue used for direct enzyme extraction also included 8 normal (age range 52-83 years), 4 non-scarred keratoconic (2246 years), 4 scarred keratoconic (18-25 years) and 4 traumatically scarred corneas (28-73 years). The proteases present in soluble protein preparations from the media of the cultured keratocytes and from intact corneal tissues were analysed and quantified by assaying against nitrophenyl acetate as substrate and by substrate (gelatin) gel electrophoresis.

The results obtained by assaying aliquots of the soluble protein extracts of either keratocyte culture medium or corneal stromal tissue, indicated that total protease activity was significantly higher in nonscarred keratoconic samples than in either normal or traumatically scarred samples (Figs. 1,2). Furthermore, since activity was inhibited by metal ion chelators such as ethylenediaminetetraacetic acid (EDTA) to the extent of $95 \%$ at a concentration of $2.5 \mathrm{mM}$ (Fig. 3) it was tentatively concluded that the majority of the secreted proteases belonged to the MMP family.

This possibility was supported by visualising individual actvities on SDS-gelatin polyacrylamide gels. A typical zymogram showing the predominant gelatinase activities secreted by normal, KCS, $\mathrm{KCS}_{(\text {scar) }}$ and $\mathrm{Scar}_{\text {(trauma) }}$ corneal keratocytes in vitro is presented in Fig. 4. By incubating SDSgelatin polyacrylamide gels of similar samples in assay buffer containing EDTA $(1 \mathrm{mM})$ after electrophoresis, cleared bands failed to develop (data not shown).

From the summated activity data (Tables I, II), it was concluded that the predominant gelatinase activity secreted by normal corneal keratocytes was of molecular weight $\left(\mathrm{M}_{\mathrm{r}}\right) 65000$, that $\mathrm{KCS}$ and 


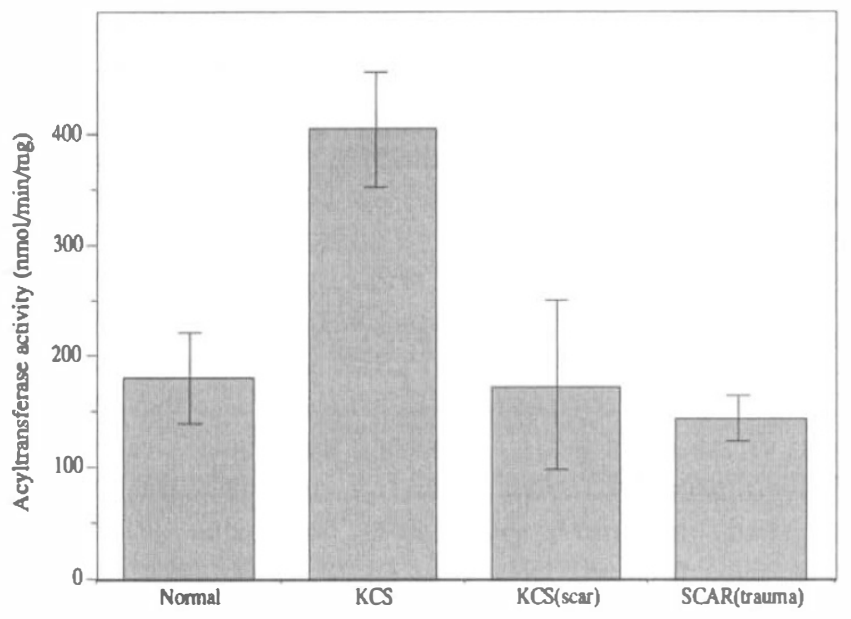

Fig. 1. Histogram of acyl transferase activity in protein preparations from serum-free media of confluent primary cultures of keratocytes derived from normal, $K C S$, $K C S_{(\text {scar) }}$ and $S_{\text {car }}$ (trauma) corneal tissue.

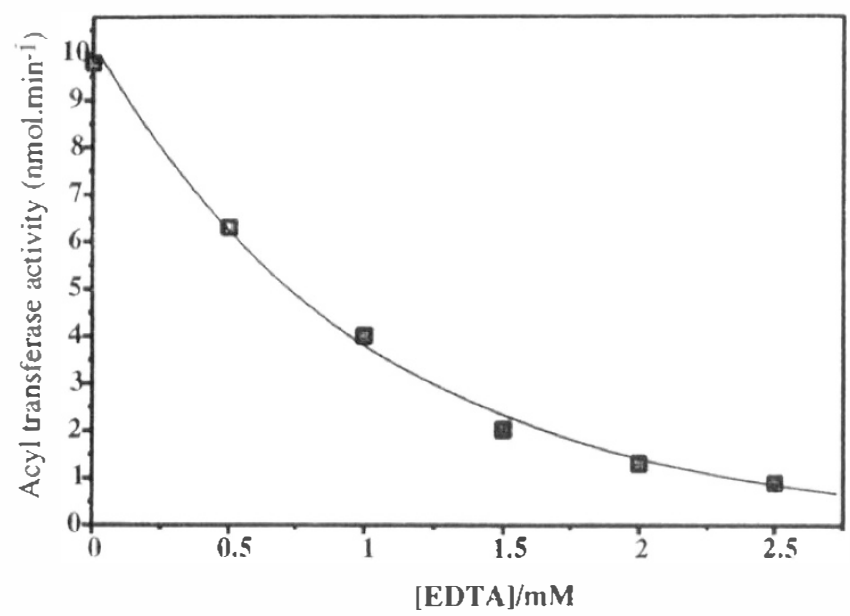

Fig. 3. Plot of acyl transferase activity against EDTA concentration. The relationship is logarithmic and the protein preparation assayed was obtained from the culture medium of KCS corneal keratocytes.

$\mathrm{Scar}_{\text {(trauma) }}$ corneal keratocyies produced an additional activity of $\mathrm{M}_{\mathrm{r}} 61000$, and that $\mathrm{KCS}_{\text {(scar) }}$ keratocytes generally produced little or none of the latter gelatinase activity. Attempts to locate the gelatinase activities on gelatin polyacrylamide gels prepared and run in the absence of SDS, in various buffer systems, failed. The proteolytic enzymes, as secreted, apparently exist in an inactivated form.

Although the acyl transferase activity in all protein preparations was inhibited by EDTA, it was also found to be independent of added $\mathrm{Ca}^{2+}$ salts. By contrast, the gelatinase activities in these protein preparations, as detected after SDS-PAGE (polyacrylamide gel electrophoresis), required the addition of $\mathrm{Ca}^{2+}$. Maximum activity was observed at calcium chloride concentrations above $1 \mathrm{mM}$. These observations support the suggestion that the proteases secreted by corneal keratocytes are predominantly MMPs. The metal ion that is held at the catalytic centre of all MMPs is $\mathrm{Zn}^{2+}$. A second $\mathrm{Zn}^{2+}$

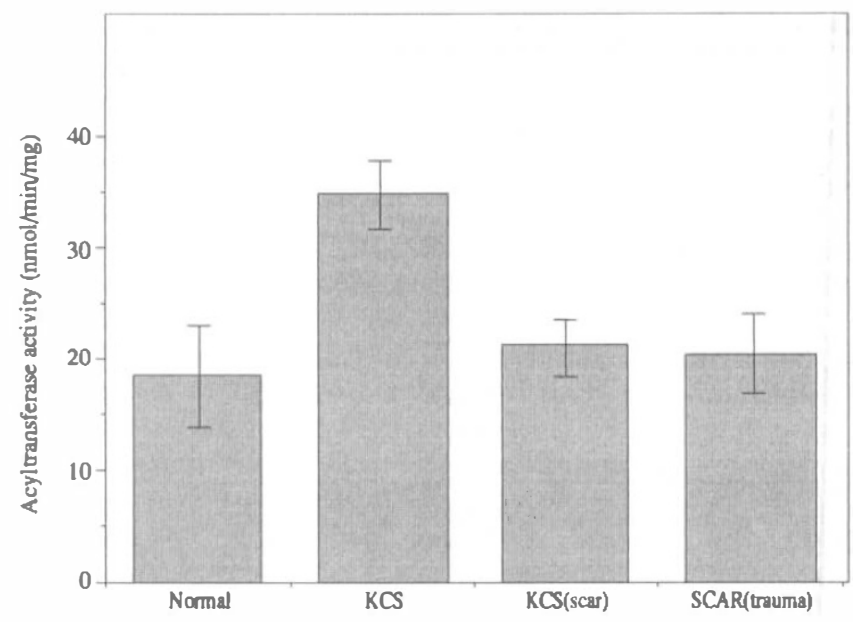

Fig. 2. Histogram of acyl transferase activity in the soluble protein fractions of stromal tissue obtained from normal, $K C S, K C S_{(\text {scar })}$ and Scar (trauma) corneal buttons.

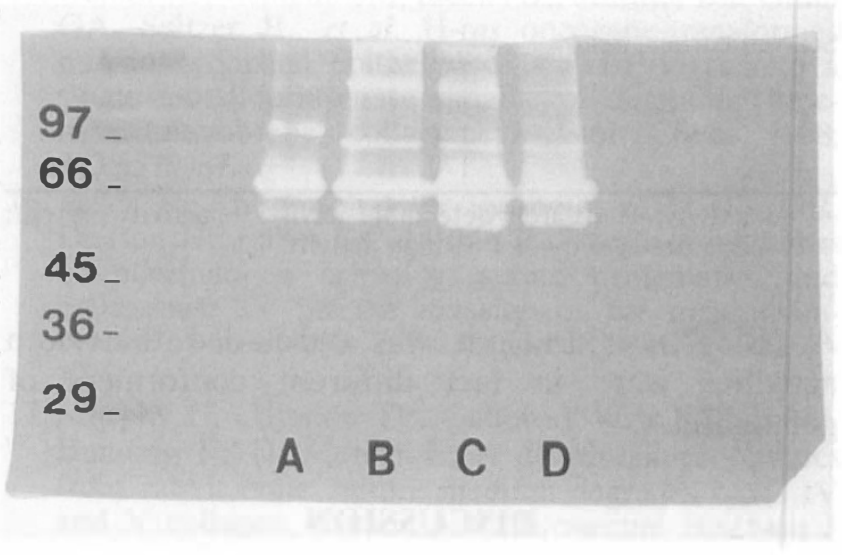

Fig. 4. Zymogram of gelatinase activities secreted by normal (lane A), KCS (scar) (lane B), KCS (lane C) and Scar $r_{\text {trauma) }}$ (lane D) keratocytes cultured in vitro. The running positions of the molecular weight $\left(\times 10^{-3}\right)$ standards are marked. The protein samples were of similar concentration.

ion and $\mathrm{Ca}^{2+}$ are also integral components of the active protein. ${ }^{12}$ Presumably, therefore, EDTA effectively displaces both $\mathrm{Zn}^{2+}$ and $\mathrm{Ca}^{2+}$ from these enzymes. Whereas $\mathrm{Zn}^{2+}$ appears to be involved in acyl transfer, $\mathrm{Ca}^{2+}$ either functions in a subsequent reaction in the catalytic mechanism or plays an important role in maintaining the active conformation of the enzyme.

Thiol reagents rapidly catalyse the decomposition of nitrophenyl acetate. It was not possible, therefore, to assess the effect of such reagents on acyl transferase activity. However, both mercaptoethanol and dithiothreitol (DTT) were found to be potent inhibitors of the 65000 and $61000 \mathrm{M}_{\mathrm{r}}$ gelatinase activities visualised after SDS-PAGE. Since thiol sensitivity ${ }^{13}$ is a property of gelatinase A (MMP-2) that is not shared by collagenase (MMP-1) or stromelysin (MMP-3), and since the 65000 and $61000 \mathrm{M}_{\mathrm{r}}$ activity bands co-migrated with major bands produced by an authentic sample of gelatinase 
Table I. Protease activities secreted by keratocytes

\begin{tabular}{|c|c|c|c|}
\hline \multirow[b]{2}{*}{ Samples } & \multirow{2}{*}{$\begin{array}{c}\text { Transferase } \\
\text { activity } \\
(\mathrm{nmol} / \mathrm{min} / \mathrm{mg})\end{array}$} & \multicolumn{2}{|c|}{ Gelatinase acivity } \\
\hline & & $65000 \mathrm{kDa}$ & $61000 \mathrm{kDa}$ \\
\hline \multicolumn{4}{|l|}{ Normal } \\
\hline 1 & 240 & ++ & $+1-$ \\
\hline 2 & 130 & ++ & $+1-$ \\
\hline 3 & 120 & ++ & $+1-$ \\
\hline 4 & 190 & ++ & $+1-$ \\
\hline 5 & 150 & ++ & - \\
\hline 6 & 160 & ++ & - \\
\hline 7 & 200 & ++ & + \\
\hline 8 & 230 & + & - \\
\hline \multicolumn{4}{|c|}{ Keratoconus: KCS } \\
\hline 1 & 550 & +++ & +++ \\
\hline 2 & 360 & +++ & +++ \\
\hline 3 & 310 & + & +++ \\
\hline 4 & 400 & +++ & ++ \\
\hline \multicolumn{4}{|c|}{ Scarred keratoconus: $\mathrm{KCS}_{\text {(scar) }}$} \\
\hline 1 & 260 & ++ & + \\
\hline 2 & 240 & $+1-$ & $+1-$ \\
\hline 3 & 100 & $+1-$ & $+1-$ \\
\hline 4 & 90 & $+1-$ & $+1-$ \\
\hline \multicolumn{4}{|c|}{ Scarred cornea: Scar $_{\text {(trauma) }}$} \\
\hline 1 & 150 & +++ & +++ \\
\hline 2 & 110 & ++ & + \\
\hline 3 & 144 & +++ & +++ \\
\hline 4 & 170 & +++ & +++ \\
\hline
\end{tabular}

,- no activity; $+/-$ barely detectable actvity; + , activity present; ++ , moderate activity; +++ , high activity.

A (Biogenesis Ltd), it was concluded that both activities were in fact different conformers of gelatinase $\mathrm{A}$.

\section{DISCUSSION}

The results presented in this paper indicate that a single gelatinase of $M_{r} 65000$ and characterised as gelatinase A (MMP-2) is the major protease secreted by normal corneal keratocytes both in vitro and in vivo. This finding is essentially in agreement with the observations of previous authors, with the exception of some variance in the estimated molecular weight of the enzyme from and between published data..$^{7,14}$

In initiating this investigation of the role that proteases, particularly the MMPs, may play in inducing keratoconus, the possibility was considered that the protease activities detected may relate to wound-healing processes rather than to the primary disease. Thus keratoconic corneal samples were divided into two groups, dependent upon whether they were clear or scarred. Additionally, traumatically scarred corneal samples were included in the study.

By comparison with the total protease activity secreted by normal keratocytes, the total protease activity secreted by KCS keratocytes, as determined by acyl transferase specific activity measurements, was high. This enhanced activity correlated with the appearance of an additional band of gelatinase activity of approximate $M_{r} 61000$. This gelatinase species was also a component of the proteases
Table II. Protease activities in homogenised corneas

\begin{tabular}{|c|c|c|c|}
\hline \multirow[b]{2}{*}{ Samples } & \multirow{2}{*}{$\begin{array}{c}\text { Transferase } \\
\text { activity } \\
\text { (nmol/min/mg) }\end{array}$} & \multicolumn{2}{|c|}{ Gelatinase acivity } \\
\hline & & $65000 \mathrm{kDa}$ & $61000 \mathrm{kDa}$ \\
\hline \multicolumn{4}{|l|}{ Normal } \\
\hline 1 & 19 & + & - \\
\hline 2 & 16 & + & - \\
\hline 3 & 19 & + & - \\
\hline 4 & 11 & + & - \\
\hline 5 & 22 & + & - \\
\hline 6 & 23 & + & - \\
\hline 7 & 15 & + & - \\
\hline 8 & 20 & + & - \\
\hline \multicolumn{4}{|c|}{ Keratoconus: KCS } \\
\hline 1 & 37 & + & + \\
\hline 2 & 38 & + & ++ \\
\hline 3 & 32 & + & + \\
\hline 4 & 31 & + & + \\
\hline \multicolumn{4}{|c|}{ Scarred keratoconus: $\mathrm{KCS}_{(\mathrm{scar})}$} \\
\hline 1 & 21 & $+1-$ & $+/-$ \\
\hline 2 & 24 & $+1-$ & $+1-$ \\
\hline 3 & 22 & + & ++ \\
\hline 4 & 17 & + & $+/-$ \\
\hline \multicolumn{4}{|c|}{ Scarred cornea: Scar $_{\left(\text {trauma }_{)}\right.}$} \\
\hline 1 & 18 & + & + \\
\hline 2 & 22 & + & + \\
\hline 3 & 15 & + & ++ \\
\hline 4 & 24 & + & ++ \\
\hline
\end{tabular}

,- no activity; $+/-$ barely detectable actvity;
,++ moderate activity;,+++ high activity.

produced by Scar $_{\text {(trauma) }}$ keratocytes but not, surprisingly, by $\mathrm{KCS}_{\text {(scar) }}$ keratocytes. Although the appearance of the 61000 gelatinase activity in the KCS and Scar $_{\text {(trauma) }}$ samples represents an abnormal situation as concerns corneal metabolism, it is, in fact, a welldocumented form of gelatinase $\mathrm{A} .{ }^{15,16}$ That this particular gelatinase activity may play a significant role in inducing keratoconus is an attractive proposition. Though it will not cleave interstitial collagens (types I, III), activated gelatinase A hydrolyses type IV collagen, ${ }^{17,18}$ the major structural element of all basement membranes; disruption of the epithelial cell basement membrane and of Descemet's membrane are pronounced pathological features in keratoconic corneas. The mechanism for generating the $61000 \mathrm{M}_{\mathrm{r}}$ gelatinase $\mathrm{A}$ in keratoconic corneas is unknown. A number of previous authors have suggested that it represents the active form of gelatinase A generated from the higher molecular weight species by autocatalytic cleavage of the $\mathrm{N}$ terminal domain upon removal of the specific MMP inhibitors known as TIMP-1 and TIMP-2. ${ }^{19-22}$ Although it has also been reported that both these inhibitors exist in culture medium of keratocytes derived from normal corneas, in association with a single gelatinase activity of $\mathrm{M}_{\mathrm{r}} 68000,{ }^{14}$ and that their modification gives rise to increased gelatinolytic activity in keratoconic corneas, ${ }^{9}$ we have found no evidence for such an activation mechanism. Both the 65000 and $61000 \mathrm{M}_{\mathrm{r}}$ gelatinase $\mathrm{A}$ species appear to be secreted in corneal stromal tissue in inactive 
forms; if the latter species were produced through lack of TIMP, then it is considered unlikely that it would be held in an inactive form by TIMP. Furthermore, both gelatinases are activated by SDS treatment followed by electrophoresis on SDSgelatin polyacrylamide gels. While this treatment dissociates hydrogen-bonded proteins, it will not dissociate TIMP/MMP that is complexed by the formation of disulphide bridges. In the context of keratoconus, therefore, the presence of the 61000 gelatinase A species does not signify necessarily that this enzyme species is responsible for inducing the condition, but the possibility remains that an endogenous component of the corneal stroma acts in a similar manner to SDS in selectively activating this enzyme.

In conclusion, the mechanism by which gelatinase $A$ is activated and inactivated in keratoconic corneas is poorly understood and is the subject of current research endeavours.

We thank Mr A. Tullo (Manchester Eye Hospital) and Mr S. D. Cooke (Bristol Eye Hospital) for donating specimen corneal samples, and Dr J. van der Stappen for the gift of gelatinase A. We are also very grateful to Col S. Gaussen and the NERC for financial support.

Key words: Cornea, Gelatinase, Keratoconus, Keratocyte, Matrix metalloproteinase (MMP)

\section{REFERENCES}

1. Maguire LJ, Meyer RF. Ectatic corneal degradations. In: Kaufman HE, McDonald MB, Barron BA, Waltman SR, editors. The cornea. Edinburgh: Churchill Livingstone, 1988:485-510.

2. Vail A, Gore SM, Bradley BA, Easty DL, Rogers CA. Corneal transplantation in the United Kingdom and Republic of Ireland. Br J Ophthalmol 1993;7:650-6.

3. Teng CC. Electron microscopic study of the pathology of keratoconus: I. Am J Ophthalmol 1963;55:18-47.

4. Chi HH, Katzin HM, Teng CC. Histopathology of keratoconus. Am J Ophthalmol 1956;42:847-60.

5. Bron AJ, Tripathi RC, Harding JJ, Crabbe MJC. Stromal loss in keratoconus. Trans Ophthalmol Soc UK 1978;98:393-6.

6. Kao WWY, Vergnes JP, Ebert J, Sundar-Raj CV, Brown SI. Increased collagenase and gelatinase activities in keratoconus. Biochem Biophys Res Commun 1982;107:929-36.

7. Fini ME, Yue YJT, Sugar J. Collagenolytic/gelatinolytic metalloproteinases in normal and keratoconus corneas. Curr Eye Res 1992;11:849-62.

8. Ihalainen A, Salo T, Forsius H, Peltonen L. Increase in - type I and type IV collagenolytic activity in primary cultures of keratoconus cornea. Eur $\mathbf{J}$ Clin Invest 1986;16:78-84.

9. Brown D, Chwa MM, Opbroek A, Kenney MC. Keratoconus corneas: increased gelatinolytic activity appears after modification of inhibitors. Curr Eye Res 1993;571-8.

10. Unemori EN, Werb Z. Reorganisation of polymerised actin: a possible trigger for induction of procollagenase in fibroblasts cultured in and on collagen gels. J Cell Biol 1986;103:1021-31.

11. Hall BG, Hartl DL. Regulation of newly evolved enzymes. II. The ebg repressor. Genetics 1975;81:42735.

12. Murphy GJP, Murphy G, Reynolds JJ. The origin of matrix metalloproteinases and their familial relationships. FEBS Lett 1991;289:4-7.

13. Salvesen G, Nagase $H$. Inhibition of proteolytic enzymes. In: Beynon RJ, Bond JS, editors. Proteolytic enzymes: a practical approach. Oxford: IRL Press, 1990:83-104.

14. Brown B, Chwa M, Escobar M, Kenney MC. Characterisation of the major matrix degrading metalloproteinase of human corneal stroma: evidence for an enzyme/inhibitor complex. Exp Eye Res 1991; 52:5-16.

15. Collier JE, Wilhelm SM, Eisen AZ, Marmer BL, Grant GA, Seltzer JL, et al. H-ras oncogene-transformed human bronchial epithelial cells (TBE-1) secrete a single metalloproteinase capable of degrading basement membrane collagen. J Biol Chem 1988; 263:6579-87.

16. Reich R, Thompson EW, Iwamoto Y, Martin GR, Deason JR, Fuller GC, Miskin R. Effects of inhibitors of plasminogen activator, serine proteinases, and collagenase IV on the invasion of basement membranes by metastatic cells. Cancer Res 1988;48:330712.

17. Murphy G, Cawston TE, Galloway WA, Barnes MJ, Bunning RAD, Mercer E, et al. Metalloproteinases from rabbit bone culture medium degrades types IV and $\mathrm{V}$ collagen, laminin and fibronectin. Biochem $\mathrm{J}$ 1981;199:807-11.

18. Seltzer JL, Adams SA, Grant GA, Eisen AZ. Purification and properties of a gelatin-specific neutral protease from human skin. J Biol Chem 1981;256:46628.

19. Murphy G, McGuire MB, Russell RGG, Reynolds JJ. Characterisation of collagenase, other metalloproteinases and an inhibitor (TIMP) produced by human synovium and cartilage in culture. Clin Sci 1981;61: $711-6$.

20. Goldberg GI, Marmer BL, Grant GA, Eisen AZ, Wilhelm S, He C. Human 72 kilodalton type IV collagenase forms a complex with a tissue inhibitor of metalloproteases designated TIMP-2. Proc Natl Acad Sci USA 1989;86:8207-11.

21. Overall CM, Wrana JL, Sodek J. Independent regulation of collagenase, $72-\mathrm{kDa}$ progelatinase, and metalloendoproteinase inhibitor expression in human fibroblasts by transforming growth factor $\beta$. J Biol Chem 1989;264:1860-9.

22. Stetler-Stevenson WG, Krutzsch HC, Liotta LA. Tissue inhibitor of metalloproteinase (TIMP-2), a new member of the metalloprotenase inhibitor family. J Biol Chem 1989;264:17374-8. 